\title{
Life-changing or trivial: Electricians' views about electrical accidents
}

\author{
Sara Thomée ${ }^{\mathrm{a}, \mathrm{b}, \mathrm{c}, *}$ and Kristina Jakobsson ${ }^{\mathrm{b}, \mathrm{c}, \mathrm{d}}$ \\ ${ }^{a}$ Department of Psychology, University of Gothenburg, Sweden \\ ${ }^{\mathrm{b}}$ Occupational and Environmental Medicine, Institute of Medicine, Sahlgrenska Academy, \\ University of Gothenburg, Sweden \\ ${ }^{\mathrm{c}}$ Occupational and Environmental Medicine, Sahlgrenska University Hospital, Gothenburg, Sweden \\ d Occupational and Environmental Medicine, Department of Laboratory Medicine, \\ Faculty of Medicine, Lund University, Sweden
}

Received 20 September 2016

Accepted 19 December 2017

\begin{abstract}
.
BACKGROUND: It is well known that electrical accidents can cause physical injury. Less well known is that long-term consequences may include emotional and cognitive problems.

OBJECTIVE: To explore electricians' experiences and perceptions of work-related electrical accidents, with focus on psychological short- and long-term consequences, including how contacts with health care services and the workplace were perceived.

METHODS: Semi-structured interviews with 23 Swedish male electricians, aged 25-68, who had experienced at least one electrical accident and reported residual sensory, musculoskeletal, cognitive or emotional symptoms. Data was analyzed by means of qualitative content analysis.

RESULTS: Immediate emotional reactions included surprise, confusion, fear, anxiety, and anger; also long-term consequences were seen. Experiencing a no-let-go situation was particularly stressful. The cause of the accident, and questions about guilt and blame were central in the aftermath. Lack of knowledge and routine among health care professionals concerning electrical injury was reported, as well as lack of medical and psychological follow-up.

CONCLUSIONS: For some informants, the accident had been a life-changing event, while for others it was an event of little importance. Adequate handling at the workplace, and from health care personnel, including follow-up, could facilitate rehabilitation and return to work.
\end{abstract}

Keywords: Electrical injury, occupational injury, qualitative research, psychology, trauma, work ability

\section{Background}

Electrical accidents occur in many settings, and affect professionals as well as lay persons. In Sweden, the number of fatalities attributed to electrical accidents has steadily decreased during the last 50 years thanks to safety regulations. Still, the risk for electrical accidents is an everyday reality for professional electricians. Mechanisms of injury include the direct contact with the current or an electric arc result-

*Address for correspondence: Sara Thomée, Tel.: +46 317861 882; Fax: +46 31 7864628; E-mail: sara.thomee@psy.gu.se. ing in thermal burn injuries, internal neuromuscular injuries, and secondary falls and hits from objects. The physical consequences of electrical accidents can be instantly evident, but may also appear insidiously after an initially uncomplicated event [1], and can have long term effects on health and work ability.

Less well known are the long term emotional and cognitive consequences of electrical accidents [1-6]. Reduced mental well-being and psychiatric problems such as depression, anxiety, phobias and post-traumatic stress disorder (PTSD) have been reported, as well as memory and concentration 
difficulties $[1,4,6]$. Potentially life-threatening events are an obvious explanation for such psychological reactions, but it has also been hypothesized that direct damage of the brain from the electrical current may occur [6]. Also, the dealing of guilt, blame and responsibility is important for adaptation after an accident.

Lack of knowledge about the broad consequences of electrical accidents may lead to neglect of the emotional issues by health care providers since they, as well as electricians themselves and their employers, usually focus on the initial acute physical injuries. Moreover, most electricians are males, working in male-dominated occupational settings. Thus, also at play are norms about masculinity, favoring toughness and stoicism, acceptance, and normalization of risk [7].

Most previous studies on consequences after electrical injuries in a long-term perspective, whether qualitative or quantitative, emanate from specialized trauma, burn or rehabilitation centers [2, 8-10]. Thus, the findings from such studies will likely not reflect the broad spectrum of minor and major consequences in the aftermath of an electrical accident. The present study is part of a Swedish research project in which a questionnaire study on electrical accidents had a study population based on electricians' union member lists and workplace electrical accident reports [5]. Electricians who reported persisting symptoms which they themselves attributed to an electrical accident were invited to a clinical investigation of sensory and motor function [11], and cognition [12]. The investigation also included a semi-structured interview. This qualitative study is thus a case-series based on a nation-wide working population of electricians. The main purpose of the interviews was to gain knowledge about factors of importance for long-term effects and to better understand the consequences for the individual from a psychological point of view. Such knowledge can contribute to improved care and treatment from the health care services, improved handling from the workplaces, and over-all improved preventive strategies to reduce long-term consequences after electrical accidents.

Thus, the aim was to explore male electricians' experiences and perceptions of work-related electrical accidents, with focus on the psychological shortand long-term consequences. The study also had the aim to explore how the injury victims perceived their contacts with health care services and the workplace. The specific research questions included;
What were the electricians' reactions at the time of the accident?

What were the immediate reactions?

Which thoughts and feelings were evoked in the situation and in the aftermath of the accident?

What were the long term consequences of having experienced an electrical accident?

Which emotional consequences did the accident have over time?

How was work ability affected?

What significance has the accident had in a lifeperspective?

What were the experiences with the health care services?

How did medical providers respond?

Was there anything lacking in the contact with health care?

How was the response at the workplace?

\section{Methods}

\subsection{Participants}

Twenty-three Swedish male professional electricians, who had experienced at least one work-related electrical accident, participated in a clinical study focusing of long term effects of electrical injury. The participants were recruited from a two-step postal questionnaire study, enrolling electricians from the Swedish Electricians' Union (study base $n=4000$ ) and the Registry of work-related disorders at the Swedish Work Environment Authority (study base $n=343$ ). The first questionnaire (response rate approx. $50 \%$ ) identified those who had experienced an accident that involved electrical current passing through the body. These $(n=1156)$ were sent a second questionnaire which included questions about the accident and potential immediate and long-term symptoms (response rate $49 \%, n=561$ of which 523 were male electricians) [5]. From the second questionnaire, all male electricians who reported residual sensory, musculoskeletal, cognitive or emotional health problems which they attributed to an electrical accident $(n=58)$ were invited to participate in a clinical study. Twenty-eight men agreed to participate, of which four were excluded due to medical reasons, and one later declined to participate. In total, 23 men completed the clinical study, 
which consisted of neurophysiological [11] and neuropsychological examinations [12] in addition to a semi-structured interview. The study was approved by the regional ethics committee in Uppsala-Örebro (2011/252). Written consent was obtained from all individual participants included in the study.

\subsection{Data collection}

The interviews were conducted face-to-face by a psychologist (first author), and were carried out at five regional occupational and environmental medicine clinics in Sweden (Gothenburg, Lund, Sundsvall, Umeå and Örebro) during September and October 2012. During the same day, the informant also underwent neurosensory and neuropsychological testing $[11,12]$. The interviews were based on a semi-structured interview guide with open-ended questions. The areas of query included experiences and perceptions relating to the accident, its longand short-term consequences on mental well-being, sick leave and work capacity, encounters with the health care services, and how the workplace had responded after the accident. The interview also included queries about perceived safety culture in the work places, reported elsewhere [13]. The interviews lasted between 30 and 75 minutes and were recorded and transcribed.

\subsection{Data analysis}

The transcriptions were processed according to qualitative content analysis [14-16]. The text was sorted in the areas of query (reactions at the time of the accident, emotional consequences over time, encounters with the health care services, sick-leave and work ability, response at the workplace, and the significance of the accident in a long-term perspective) and then condensed. In the next step, the condensed data was coded and categories were formed (e.g., pain, arousal, persistent distress). The analysis was kept close to the participants' statements $[14,17]$ and to the thematic topics. Central aspects and patterns, as well as the width and variety of experiences, are presented as results [14]. Representative summaries and quotes (translated from Swedish by the first author) are presented for illustration.

\section{Results}

\subsection{Description of participants}

All participants were male electricians aged 25-68 (median age 54) years. They had between 4 and 45 (median 28) years of experience of electrical work. Twelve of the 23 participants reported having experienced one severe work-related accident, while most of the remaining reported between 2 and 10 events, and two informants reported 20 events or more. The most severe accident, as of their own judgement, was the focus for the interview. The referred accident had occurred between less than one year and almost 45 (median 6) years earlier.

\subsection{The accident}

The severity of this specified accident ranged from relatively short-term shocks where the electrician was able to continue working almost immediately, to high voltage accidents resulting in extensive burns and prolonged hospital stay. Most of the specified accidents had occurred during work with low voltage $(<1000 \mathrm{~V})$, but for six of the participants, high voltage $(>1000 \mathrm{~V})$ was involved. The most common point of contact was the hand or fingers. The head had been a point of contact for three of the participants. All had reported residual health problems that they attributed to an electrical accident; the majority $(93 \%)$ had reported sensory or musculoskeletal symptoms (pain, loss of sensation, muscle weakness, muscle twitching), and $41 \%$ had reported cognitive or emotional symptoms (concentration difficulties, sleep problems, anxiety, fatigue).

About one third of the specified accidents occurred when the informant worked alone. It was common that the electricians had worked without shut-down of the power, either intentionally or because they assumed that it was done. About half of the accidents were due to unintentional contact with electric charge when the electrician had thought he could perform the task with the power set. In six cases the electrician mistakenly thought the power was off, mostly attributable to mis-communication at the worksite. The remaining accidents were caused by technical errors, including a few that were due to chance or unknown reasons.

\subsection{Reactions at the time of the accident}

When asked about how it felt to be exposed to electrical current, a broad range of physical and emotional reactions were described by the electricians. Immediate physical reactions that were mentioned included pain, arousal, auditory, visual and kinesthetic sensations, and dizziness or loss of consciousness. Immediate emotional reactions were confusion and 
surprise, fear, anxiety and agony, and anger, blame and guilt. It was sometimes difficult to distinguish emotional from physical reactions. Some reactions emerged in the aftermath of the accident or even later, and some persisted over time (see 3.4 Long-term emotional consequences over time).

\subsubsection{Pain}

Pain and discomfort were dominant experiences. Many informants received minor burns from contact with the electrical current, and three men had extensive burns. Secondary injuries, mainly due to falls, including tongue damage, scrapes and bruises, were common. For some, pain had been immediate and intense but swift, and for some, it lasted for days, weeks or years, mostly depending on the evident extent of injury but sometimes also without clear causes. Pain could appear later, e.g., the next day, in the exposed limb or body part. Some also described a lack of pain at the time of the accident; that they felt nothing in spite of extensive damage.

First of all, it got very hot-like a 1000 degrees! (...) It hurt like hell.

\section{I remember I was running around screaming from the pain.}

It hurt for a while but I didn't really react any differently the next day than if I'd cut myself with a knife or something, and you often cut yourself in the fingers.

\subsubsection{Arousal}

Some described an increase in heart rate and a state of arousal in the aftermath of the accident. A few were overwhelmed by a rush or a raging energy.

I had the shakes. I was a bit wound up. That day and the next. (...) The adrenaline is pumping, you get kind of... It lasted for a day or two. Then my arm hurt. And then it disappeared, I thought about something else.

I wanted to run... an adrenaline rush. (...). I wanted to run a marathon but didn't have the energy to walk a meter.

They [co-workers] had to throw themselves on top of me because I was completely mad. (...) I was fighting and screaming, furious. But I don't remember it.

\subsubsection{Auditory, visual, and kinesthetic sensations}

There were participants that described the electrical shock as a shaking or trembling sensation: "jittery", "one big vibration". Some had auditory or visual perceptions that only they themselves could perceive.

Twice there was bzz bzz. (...) I saw a shiny white glow, maybe for microseconds.

There were green spots that ran back and forth in my head, I guess it was the hertz.

A crackling sound.

There were also descriptions of feeling the pulses of the electrical current, referred to as rapid strokes.

Ifelt the pulses, the 50 periods. It hammered like a hammer.

As if someone hit me with a baseball bat with quick strokes, really quick over the chest. It shook like a machine gun. It was real strokes.

Some electricians stated that they had felt the current's path in the body.

The current went in through the left hand and then through the body and out through the right hand. And then I started cramping up bit by bit [points to his arm]. I really felt how first the hand began to flex its muscles, and then finally when it came here to the chest. (...). I fainted when it came to the chest. The pain.

\subsubsection{Dizziness or loss of consciousness}

In the foregoing postal survey almost all participants (19 of 23) had reported that they had felt dazed at the time of the accident, and eight had lost consciousness. During the interview an additional few men reported that they had a few seconds that were unaccounted for, and that they subsequently had learned that they had been for example screaming or doing something else that they were unaware of. Most had experienced loss of consciousness for only a short while and woke up, e.g., as they hit the ground after a fall. One man woke up in the ambulance after several minutes, and one man with extensive burns had been sedated for over a week in hospital. He had no memories of the event; the last thing he recalled was from on his way to work on the day of the accident. 


\subsubsection{Confusion and surprise}

A sense of confusion and surprise was common. The electrical shock had come without warning, from out of nowhere.

\section{I had no time to think or to get scared.}

For some, the first thoughts were; What happened? How did it happen?

I thought the roof had fallen in. It was like I got hit on the head.

Even after a very brief loss of consciousness it could be perplexing to wake up, e.g., on the floor after a fall. Where am I? Why is the ladder over there? and it could take a minute or two to understand what had happened. The next question may then be where the current came from. Some of the electricians had immediately investigated and found the error before getting rest or medical attention, in order to prevent others to be injured.

\subsubsection{Fear, anxiety, agony}

Fear was a common emotion associated with the accident.

You get scared every time, you know it can strike you very bad.

You just get... scared. And paralyzed for a while. Like in shock. Even though you are aware of the risks, you get just as scared every time it happens.

Experiencing a no-let-go situation emerged as especially stressful. Alternating current can generate a severe muscle spasm that hinders the person from willfully letting go of the power source. Several of the informants had been "stuck" to the power source for some time. The victim could be completely clearheaded and know that he needs to let go, but be unable to do anything about the situation. It was reported that it was impossible to cry out or otherwise attract attention. The release may finally have come because of the body weight forcing a let-go, when the legs eventually curled or because of fainting. In some cases, a co-worker came to the rescue.

It's just like you let go of everything. You go so damn quiet. Like you're in shock. You get jittery. You become totally paralyzed. (...) Both arms got locked. It really sucked hold of my arm. You can't do much.

You get stuck and then you just start to shake. You can feel these hertz waves. (...) Like I said, time went quite slowly, I had time to think; what happened? You get a little paralyzed, too, standing still and you wonder - you can't do anything you sort of think; what can be done? but you can't do anything. But then it [the circuit breaker] went off and I was released.

I was absolutely convinced that it was the last I ever did. I perceived it as a very long time. I tried to let go, but it wasn't possible. I tried to throw myself backwards, but the basket was too small. I couldn't move my body. I just crept together and sat there, shaking.

The latter electrician was standing in a basket lift and came loose after about a half minute because the driver of the tractor became aware that something was wrong from hearing screams. The driver backed the tractor so that the electrician could release from the source. The electrician himself did not remember screaming. Another electrician described it like this:

It's a horrible experience. It's difficult to describe. There's like a quiver. You can't move your hands. (...) But I eventually fell. When my legs curled I fell to the floor. I think I was stuck for 10 seconds. Maybe longer.

For some, it was difficult to find words to describe the experience and some became notably emotionally affected talking about it. Words like death agony were used.

I was convinced that this was the end. I just felt everything running out. It was... [sighs]. I find it hard to talk about, still. It's tough. I had time to think that I will die if I don't let go. I had a lot of flashbacks of my family and everything. I had time to think a lot. It wasn't many seconds, maybe 3 seconds at the most. I had time to think a lot, I had time to think; I will die if I don't let go. (...) I had death agony. (...) I couldn't let go. I wanted to open my fingers but they just clasped. It was horrible. I'm going to die, I thought.

\subsubsection{Anger, blame and guilt}

Among the recurrent immediate emotional reactions were anger and frustration about having suffered an accident. Self-blame concerning that one may have been careless and thus caused the electrical shock, for example by not shutting down the power, was fairly common.

Most of all, I felt stupid to have done it. It's often like that, you feel stupid for making a mistake. 
There's no one to blame, it was entirely my own fault. If I had taken my voltage tester I would have seen that it [the power] was set. That was the big mistake.

You're most of all angry with yourself, because it's really so easy to just cut the power.

There was also anger and frustration about coworkers' or other persons' actions and possible involvement in causing the accident.

The lack of respect for others' health and lives can make me very angry!

\subsection{Long-term emotional consequences}

Emotional reactions to the accident that seemed to reside or develop over time were categorized as persistent distress, pondering existential questions and residual resentment.

\subsubsection{Persistent distress}

For some informants, fear and anxiety persisted for a long time. Thoughts, feelings, and vivid memories could emerge when the electricians were reminded of the accident in other contexts. To perform the same type of work tasks as at the time of the accident, visit the same work site, or even recognize a smell, could serve as a reminder. This could also affect work ability (discussed further down). To talk about the incident in the interview situation was emotionally painful for some of the men. Feeling depressed after the accident was also mentioned.

Counseling had been a way to come to terms with psychological dysfunction after the accident for a few of the informants. Among the informants were also persons who had a history of other life events that may have created a vulnerability that reinforced their emotional responses to the accident. It was thus not always clear what was the root cause of prolonged distress.

\subsubsection{Pondering existential questions}

The accident could lead to confrontation with profound existential questions. Near-death experiences at the time of the accident were described. For example, one electrician who suffered from cardiac arrest at the accident described that he was beside his body and could register everything that happened. He claimed to have witnessed how he received cardiopulmonary resuscitation at the injury scene, and that he lost consciousness on the way to the hospital. Another electrician described how he was brought back to consciousness from a beautiful place he was reluctant to leave. These kind of experiences could be difficult to share with others and raised existential questions for the subjects. Existential thoughts and emotions could arise long after the immediate crisis has subsided.

Thoughts about being near-death came later, months later.

Recurrent in the interviews were retrospective thoughts about what could have happened; that it could have ended worse. Some pondered why it had gone well for themselves, but not for others. There was also relief and gratefulness that it went as well as it did.

I have read that the heartbeat can be at the wrong point and that just a little electrical current is enough if you're unlucky, for you to... faint.

When you think about it, you know that people die every year from electricity, so I could have been part of those statistics.

How come I survived? (...) There was this 4 year old who touched a heater that lacked paint - and there was no residual current circuit-breaker, so he got 230 volts in him... So, why him and not me? A little of that... those kind of thoughts are sometimes in the back of my head.

\subsubsection{Residual resentment}

The question about the actual cause of the accident, and thoughts about guilt and blame in the aftermath of the accident was a central theme. For some men, the accident had not been investigated satisfactory and therefore they still had questions about what had caused the accident, and to what extent human factors had played a role. Others felt that they had been treated unfairly or had been incorrectly identified as causing the accident. Residual disappointment, anger, and lack of trust towards the employer, was expressed. There was also resentment about the role of organizational and societal factors.

I can say that I was very angry. I was angry at the system. Simply put, it has to do with deregulation, nothing else.

\subsection{Encounters with health care services}

Most of the informants (16 of 23) had visited an emergency room after the accident. They had been 
taken there by a co-worker or supervisor, or by ambulance. One person drove to the hospital himself.

\subsubsection{Decisions to seek care}

For some, there was no question about the need to seek medical care because of obvious injury. For others, it was a routine to seek medical care after accidents involving electric current passing through the body, regardless of extent of injury,

I was on all fours and this guy said, "[Name] what the heck are you doing, are you sleeping?” All I said was "I've had electrical current through my body, I can't do anything, call an ambulance." (...) It only took a minute and then everybody was there, managers and all. I don't know how long the ambulance took... not long at all.

In some cases, the hospital visit was preceded by uncertainty whether to seek care or not, and had depended on the advice of others.

I was dazed but still clear-minded. (...) But then I got very shaky. I guess I was in shock. My coworker finished the job and then came down to get me (...) and we went down to the shop and then this other co-worker came who had his wife with him, and she was an assistant nurse I think. They were just visiting. And she said you have to go [to the hospital] She checked my pulse. I was very shaky and nervous. (...) So the co-worker who came with his wife, he drove me to the hospital.

We [informant and co-worker] went to the car and discussed what to do. If we should bother about it. Because it's really difficult to know. We talked about it, that it was probably a pretty big blow. So, we called the occupational health services and she told us to go to the closest emergency room.

Reasons for not seeking medical care was mostly explained either by not having perceived the shock to be hazardous ("I survived!"), or that it was not a work place routine, or because of not knowing that one should seek medical care after electrical shocks. Some of the accidents had happened many years back in a time when the individual electrician and/or the workplace lacked sufficient knowledge about the risks with electrical accidents. Also, attitudes towards safety and health risks seemed to play an important role for the decision to seek care or not.

But I was quite young then. So, I kind of just shook it off and kept going.
I hadn't the slightest thought of driving to the hospital. We didn't have that kind of safety attitude at our small firm. But later, at the larger electrical company we took courses and so on... that if we were exposed to electricity, we should see a doctor. (...) If I had been at the larger firm, I would have gone up [to the hospital], I would have, definitely. Because I really think it was that serious.

Another reason for not seeking medical care was to avoid the event to be noticed.

You don't want to go to the hospital because then you feel like you have to leave work and explain what you have done.

\subsubsection{Professional care}

Among those who went to a medical care unit, most went through ECG examinations, blood tests, and observation for a few hours up to a day or two. Three of the informants suffered more extensive burns and were treated between one week and three months in hospital. In some cases, the electrician had been sent to a larger hospital or a specialist clinic if the first instance did not have sufficient resources. Those who had been treated for a longer time in hospital were generally satisfied with the treatment and how they had been received. They appreciated the staff and considered them to be professional. Among the rest, there were more varied experiences (further below).

I only needed to enter and tell the reception that it concerned an electric shock and the doors opened straight up and I was welcome in. They took really good care of me. It was very comforting. Straight to ECG and more.

\subsubsection{Lack of knowledge and practice}

Among the negative experiences, a recurrent theme was a lack of knowledge and experience concerning electrical injury among the medical staff. Several informants reported that they had been asked if they had been exposed to "household" or "industrial" electricity, and they were told that "household" electricity was not hazardous. This was upsetting, because from the electrician's perspective, this distinction is false. (In Sweden and Europe, general-purpose electric power is 230 volts). The victims were also sometimes met with uncertainty as to which examinations should be done. In some cases, the electrician himself had to give suggestions. 
They don't really know what to do at the hospital. That's really the problem. (...) A funny question they always ask: "Is it industrial power or household power?" That's absolutely crazy. It's the same power. (...) It's just as if household electricity isn't that dangerous. Because it's always household electricity I handle and yet I work in industry, so we handle up to 1000 volts.

It's beneath contempt! No-one knows what to do. They believe that 230 volts isn't dangerous. And that 400 volts is dangerous. It's the current that is dangerous, not the voltage.

Everyone is very nice, but there's an ignorance about what to do. (...) I had to tell them: "You have to do all the examinations! I don't care what you say, we have been informed by the union!"

\subsubsection{Lack of psychological care}

Commonly, the electricians had not been asked about their mental wellbeing at the time of the accident. Some argued that this wasn't anything that they missed. For some, however, the lack was apparent. One electrician who felt stressed and depressed after the accident, expressed that he wished that the doctor or other health professionals had asked something about what had happened. He felt that talking it through would have facilitated the time that followed the accident. Another electrician had indeed been asked about his mental wellbeing, but pointed out that the psychological side effects came later and then no one asked. However, some of the informants had been helped to process negative experiences and fears after the accident through psychotherapy, which had been offered through the company or occupational health services.

\subsubsection{No follow-up}

Only a few of the informants obtained any medical follow-up from the health care services. It was common to be sent home after the routine examinations and observation period, with no further contact. The persisting musculoskeletal or sensory symptoms that many of the informants attributed to electrical injury had in most cases not been investigated. The lack of follow-up concerned also mental wellbeing and how the victim had coped with emotional reactions to the accident.

I have missed having a follow-up, after five or ten years, because I feel that I got worse. You sort of believed that if they did a final inspection then everything was alright.

This is the first time I talk to anyone who isn't an electrician about this.

Several of the informants felt that participation in the present clinical research study, which included sensory-motor and neuropsychological examinations, was a follow-up, and they expected answers about health problems they attributed to the electrical injury.

\subsection{Sick leave and work ability}

Most participants had not been on sick leave after the accident. Some were able to continue to work after a short break, while others took it easy the rest of the day or stayed home from work for a few days. Among seven men who were on sick leave for more than a week, most had returned to work directly to full time. For a few, the accident had led to a prolonged sick leave (up to several years) and extensive rehabilitation activities. One participant had the accident a fortnight before his retirement day, and he never returned to work. In terms of work ability, reduced capacity in relation to work's physical, but also psychological, demands were reported to a varying degree among the participants.

\subsubsection{Reduced capacity in relation to physical demands}

A majority of the electricians included in the study had reported persistent sensory or muskuloskeletal symptoms (which included pain, loss of sensation, muscle weakness, or muscle twitching) in the preceding postal survey. It was gathered from the interviews that work capacity was affected to varying degrees, from not at all to chronic impairment. Even among those with minor injuries it was common that work capacity was slightly reduced at least the first few days after the accident. Strength and vitality may have been temporarily reduced or they may have needed to spare the hand or arm that had been exposed to the electrical current. For some, work tasks had to be adapted for a period of time. Most informants were presently working full-time yet had persisting sensorineural symptoms or reduced dexterity [11].

My hand swelled up after a while so it was difficult to work, but I worked any way. I never went to the hospital. 


\subsubsection{Reduced capacity in relation to psychological demands}

Reduced work capacity in relation to the work's psychological demands was also reported. This included fear of performing certain work tasks after the accident, such as work at heights. The discomfort of work tasks in a similar situation as at the accident may thus affect work ability in relation to tasks the electrician normally should be able to perform.

I had big problems climbing a pole. I got halfway up because I had to try. I became so worried about everything. Anxious. Lost my confidence altogether. I tried to climb the pole, got halfway, then I couldn't get down or up. I was stuck. Well, I got down eventually but it took a while. Others had to do some of the tasks.

One electrician, who had returned to work after only a few days, described what happened when he was about to perform electrical work in the same workplace as where the accident occurred:

I was installing an outlet at the same factory and was about to take out the fuse. Already then, I started to shake. I was scared. So I called another guy. (...) He came and took out the fuses. And we tested that there was no current. Then I was about to touch the socket but I couldn't. I went to the lunch room and had a complete breakdown.

After this event, the electrician went on sick leave for several months. He received counselling through the occupational health services in order to address his fears.

Few electricians mentioned reduced cognitive capacity as a consequence of electrical injury. However, one electrician described that he had memory and concentration problems after the accident and that they affected him at work:

You get instructions to do something and then you know what to do, but when you get there, it's like there's missing pieces of a conversation - What the hell was I supposed to do more? (...) I try to use notebooks, phones and everything possible to make notes. (...) If I don't write it down straight away, it's gone.

Yet, he was unsure if these seemingly stress-related symptoms could be attributed to electrical injury or to other life events.
It seemed to get worse after the accident. (...) But since there had been a lot of stress, it's hard to tell what was what.

\subsection{Response at the workplace}

The experience of how the workplace responded to the electrical injury varied widely among the electricians. The attention that the informant received ranged from at most a brief mention of the incident to a co-worker, to wide acclaim with formal investigations, actions, and media interest in the accident. The results are categorized in the topics of incident report, satisfaction with workplace response and social support.

\subsubsection{Incident report}

In a slight majority of cases, the accident was formally reported. A few electricians had given verbal report to a manager, but no formal written report or investigation had followed. All had at least mentioned the incident to a co-worker, supervisor, or manager, for example during a break. This could evoke comments about the need to be more careful in the future but no further discussion.

The next day I told them, "I got a hell of a shock!" They shook their heads. (...) The manager listened to what I said, but what they did with the information? He said "You stupid fool!"

It was reported that a common attitude is that electrical shocks is something that "comes with the job" and nothing to talk about. It was also conveyed that one may refrain from reporting the incident, especially if the electrician was concerned about having caused the accident himself and not wanting to get attention.

It feels stupid to call the boss and say that unfortunately I got electrical current in me. "Well how did it happen?" Since it's usually because you have been careless.

\subsubsection{Satisfaction with workplace response}

Among those who were satisfied with how the accident was managed at the workplace, it was common that preventive actions had been taken following investigation of the accident. Examples given were technical solutions, increased number of voltage testers, better protective clothing, or improved procedures with the clear objective to increase work safety. Revaluation of the event in the work group or 
with the occupational health services was perceived positively.

In contrast, among those who were dissatisfied, there were descriptions of lack of understanding and support from managers, no routine to or reluctance to report, insufficient investigation including that the involved electrician's view of events was not accepted or even silenced, and no follow-up or actions taken. One electrician had been asked by the supervisor to refrain from reporting, on the grounds that it would make the company "look bad".

\subsubsection{Social support}

It was clear that social support from managers and co-workers was important and appreciated by the electricians, initially to be attended to at the time of the accident, and later if co-workers and managers kept in contact during hospitalization and sick leave. Also, to receive support in the incident report process, was appreciated. Lack of social support, however, could manifest itself as being ignored after the accident, if no-one from the workplace kept in touch afterwards, and if there was reluctance to discuss the incident, and deficient support for formal reports. One electrician described that he himself had received social support after the injury, but not his co-worker who had witnessed the severe accident.

\subsection{Significance of the accident from a life-perspective}

\subsubsection{Life-changing or trivial}

For some, the accident was a life-changing event. This was often related to the extent of injury; several informants had permanent physical problems from the accident, a few of them with long-term reduced work capacity. Some participants had vivid memories and may have needed to battle psychological issues after the accident. The long-term psychological consequences were not dependent on the extent of physical injury as much as on how the accident was experienced, e.g. having been exposed to a no-let go. Some participants had new work tasks or had chosen to switch field of work completely after the accident.

Being injured could also lead to revaluation of attitudes and perspectives on life. One informant stated that he has become a better person after the accident and that he now is mentally stronger. Another one conveyed that he has a broader perspective on life, and that he is more thoughtful and appreciative today. This electrician also said:
I had to bite the bullet and manage this. Instead of being depressed I took another road. When I regained physical capacity that is...

Others stated:

You change your perspective on life. (...) This, when I got it, it changed life totally. You think about your safety so that you can get home to the family. Everything else is unimportant. There's no job that is so important that you can give your life for it. They can say what they want. I've even told them that they can fire me, but I won't do it. It's like the doctor told me, I'm lucky to be alive.

The first thing I did when I came home [from the hospital] was to sell my motorcycle. (...) I thought, there are so many accidents, unnecessary things.

In contrast, for others the accident was trivial; an electric shock among many others. And for some informants, the accident, in spite of consequences on health and work ability, is seen as a small event in the perspective of other major life events.

\subsubsection{Greater commitment to safety}

Recurring were descriptions that the electricians had become more cautious and safety oriented at work after the accident. Examples given were to always make sure that the power is shut down before work, always use a voltage tester, use the correct equipment, and work calmly and avoid stress. Several men expressed that they now try to convey safety issues to others to a greater extent than before the accident. They tell about the accident in different contexts, and try to influence attitudes about work safety among co-workers and apprentices. Some have even moved on to work with teaching or other engagement in safety issues.

\section{Discussion}

There was a great variation in the electricians' experiences of the accident and its consequences. Immediate reactions included pain and discomfort, arousal, dizziness and loss of consciousness, surprise, confusion, fear, anxiety, and anger. Long-term consequences were also seen. These included permanent physical problems and reduced work capacity in some cases. Some had battled psychological issues, such as disabling anxiety, after the accident. The cause of the accident, and questions about guilt and blame were 
central in the aftermath. For some, the accident had been a life-changing event, while for others, it was an event of little importance. The attention the accident received at the workplace ranged from none to wide acclaim. Social support from co-workers and managers at the time of the accident and afterwards was appreciated, as well as support to do formal incident reports. A majority of the electricians had gone to an emergency room after the accident. Many were satisfied with the care, especially those who had been treated for severe injury. However, lack of knowledge and routine among health care professionals concerning electrical injury was reported, as well as lack of medical and psychological follow-up.

The interviews confirm that electrical injury can lead to obvious physical damage with lasting discomfort, reduced function and work capacity, but also have long-term psychological consequences. The nolet go phenomenon was described as particularly stressful, causing severe anxiety and agony, and could put a deep mark in the victim. Our findings are in line with other studies, reporting reduced mental wellbeing, post-traumatic stress disorders, and fears in relation to electrical work, after electrical accidents $[1,4,6,18-20]$. Furthermore, electrical injuries can have impact on cognitive functions, e.g. in the form of reduced attention and memory $[2-4,6]$. This was not a major theme among the electricians in our study. Neuropsychological investigation of the same study participants showed no objectively verifiable cognitive dysfunction on a group level. However, supplementary questionnaires showed lower mental well-being and a higher degree of subjective cognitive problems in the study group compared to controls [12].

That electrical accidents can have psychological consequences is not different from other types of accidents. However, the risk might be aggravated as electricity is "invisible", the exact injury mechanisms are unclear, and symptoms may arise with a delay and be more severe than suggested by the initial injury $[1$, 21]. This implies that the injured patient might be met with skepticism by the health care services [21]. It is illustrated by reports from participants about a lack of knowledge and examination routines concerning electrical injury victims among health professionals. Medical follow-up from the health services was usually lacking which was regretted by informants. A multidisciplinary approach may be necessary, in order to consider medical, emotional, cognitive and social impacts [22]. Not least, when planning rehabilitation and return to work; aspects concerning cognitive and psychosocial capacity may be neglected as work place adjustments tend to focus on physical capacity [23].

Co-workers and managers play an important role in the return-to-work process after injury [8, 24]. In our study, social support from managers and coworkers was important and appreciated, for example, keeping in touch during sick leave and providing support to analyze and report the accident. However, there was a large variation among the informants concerning the response at the workplace. Questions about causation, guilt, and blame were central issues, with residual anger and frustration when the accident had not been investigated properly. The attitude that electrical shocks "come with the job" is prevalent at workplaces. Norms in a masculine-dominated workplace culture may favor a risk-orientated and hard-boiled coded set of values, which in turns interact with productivity and profit pressures [25, 26]. For our informants, a central consequence after the accidents was a change of attitude to workplace safety, in terms of becoming more cautious and safetyoriented. Efforts were now made to convey safety issues to co-workers, apprentices and students. Such approaches, shifting the role of the individual from victim to actor, can be important driving forces for workplace safety culture, if accepted by the workplace and organization.

\subsection{Strengths and limitations}

A strength of this exploratory study is that it is embedded in a larger project using mixed methods - postal questionnaires, clinical investigations and semi-structured interviews - for investigation of the long-term consequences of electrical accidents [5, 11-13]. Also, the informants represent a broad spectrum of working electricians, in contrast to previous interview studies emanating from burn and rehabilitation clinics (e.g. [8, 10]). Still, it should be emphasized that the results cannot be generalized to electrical accidents among electricians in general, not the least since our study, just as other exploratory qualitative studies on this topic, comprises a rather small number of participants.

Furthermore, the final study group was selected from a survey on the basis of indicating persistent symptoms that were attributed to electrical injury. Although almost all survey participants who had experienced an electrical accident reported having acute symptoms after the accident [5], only one in ten reported having residual symptoms at the time of the 
survey. Thus the study population is highly selected, and at each stage of the selection process, the dropout rate was approximately 50\%. Moreover, there was a great variation in time that had passed since the accident, which may affect recall and the level of significance attributed to the accident. However, the themes revealed during the interviews have many similarities with findings in studies from all types of workplace accidents - a wide spectrum ranging from existential questions, guilt and blame, to the inherent conflicts between workplace safety and productivity pressures [7, 27-29].

In addition, the study group consists of professional electricians who are experts in their field and know the risks with electricity. Professional electricians account for less than half of the reported work-related cases of electrical injury [30]. It is possible that other psychological aspects than those that emerged in our study may be relevant for other professionals and lay persons with more limited knowledge about electricity.

\subsection{Implications}

Electrical accidents are relatively rare in countries with well-established electrical safety regulations. In Sweden approximately 300 annual cases are reported to the Swedish National Electrical Safety Board, and in 2015 , only about 60 work-related accidents were reported to have led to sick leave (and less than half of these concerned electricians) [30]. Even if there is substantial underreporting, this indicates that healthcare professionals encounter a limited number of electrical injury patients. This makes it particularly important with updated and documented guidelines for how to handle electrical injuries, especially in seemingly uncomplicated situations. The research project, in which this interview study is embedded, has resulted in clinical recommendations for the handling of electrical injury to prevent long-term consequences [31] as well as dissemination to the electric trade.

It is important that electricians themselves and their employers are well-educated, and have good knowledge of how to act after an electrical accident and a balanced view of the type of medical observation that should be expected. Swedish electricians are advised to always seek medical care if exposed to electrical current that passes through the body, electric arc, lightning, loss of consciousness, burns, numbness or cramping, and to contact the health care services even if the accident does not seem severe
[32]. To ensure adherence to these recommendations, information strategies to electricians as well as other occupations at risk, employers, trade unions, and vocational schools, yet need to be improved.

Follow-up of electrical injury victims seems essential. It allows the assessment of residual symptoms; symptoms that may have been over-looked in the acute situation, have debuted later, or have increased with time. A follow-up should also include assessment of cognitive, emotional or social consequences, and identify those at risk of long term psychological distress. This approach could facilitate rehabilitation and return to work. Occupational health services, if available at the workplace, can be the ideal responsible actor.

\subsection{Conclusions}

Experiencing an electrical accident at work can give a broad range of psychological short- and longterm consequences, besides obvious physical injury. For some informants, the accident had been a lifechanging event, while for others it was an event of little importance. Adequate handling at the workplace, and from health care personnel, including follow-up, could facilitate rehabilitation and return to work.

\section{Acknowledgments}

The authors wish to thank the informants and all members of the full project research group, especially Lisa Rådman, Anna Blomqvist, and Lars-Gunnar Gunnarsson. Thanks also to Kristina Gyllensten for giving valuable comments on the manuscript. The study was funded by FORTE: Swedish Research Council for Health, Working Life and Welfare (FAS 2010-0561).

\section{Conflict of interest}

The authors declare that they have no conflict of interest.

\section{References}

[1] Singerman J, Gomez M, Fish JS. Long-term sequelae of low- voltage electrical injury. Journal of Burn Care and Research. 2008;29(5):773-7. 
[2] Pliskin NH, Capelli-Schellpfeffer M, Law RT, Malina AC, Kelley KM, Lee RC. Neuropsychological symptom presentation after electrical injury. Journal of Trauma - Injury, Infection and Critical Care. 1998;44(4):709-15.

[3] Pliskin NH, Ammar AN, Fink JW, Hill SK, Malina AC, Ramati A, Kelley KM, Lee RC. Neuropsychological changes following electrical injury. J Int Neuropsychol Soc. 2006;12(1):17-23.

[4] Ramati A, Rubin LH, Wicklund A, Pliskin NH, Ammar AN, Fink JW, Bodnar EN, Lee RC, Cooper MA, Kelley KM. Psychiatric morbidity following electrical injury and its effects on cognitive functioning. Gen Hosp Psychiatry. 2009;31(4):360-6.

[5] Rådman L, Nilsagård Y, Jakobsson K, Ek Å, Gunnarsson LG. Electrical injury in relation to voltage, "no-let-go" phenomenon, symptoms and perceived safety culture: A survey of Swedish male electricians. Int Arch Occup Environ Health. 2016;89(2):261-70.

[6] Duff K, McCaffrey RJ. Electrical Injury and Lightning Injury: A Review of Their Mechanisms and Neuropsychological, Psychiatric, and Neurological Sequelae. Neuropsychol Rev. 2001;11(2):101-16.

[7] Stergiou-Kita M, Mansfield E, Bezo R, Colantonio A, Garritano E, Lafrance M, Lewko J, Mantis S, Moody J, Power N, Theberge N, Westwood E, Travers K. Danger zone: Men, masculinity and occupational health and safety in high risk occupations. Safety Science. 2015;80:213-20.

[8] Stergiou-Kita M, Mansfield E, Bayley M, Cassidy JD, Colantonio A, Gomez M, Jeschke M, Kirsh B, Kristman V, Moody J, Vartanian O. Returning to work after electrical injuries: Workers' perspectives and advice to others. Journal of Burn Care and Research. 2014;35(6):498-507.

[9] Fish JS, Theman K, Gomez M. Diagnosis of long-term sequelae after low-voltage electrical injury. Journal of Burn Care and Research. 2012;33(2):199-205.

[10] Mansfield E, Stergiou-Kita M, Kirsh B, Colantonio A. After the storm: The social relations of return to work following electrical injury. Qual Health Res. 2014;24(9):1183-97.

[11] Rådman L, Gunnarsson LG, Nilsagard Y, Nilsson T. Neurosensory findings among electricians with self-reported remaining symptoms after an electrical injury: A case series. Burns. 2016.

[12] Österberg K, Thomée S, Jakobsson K. El-olyckor i arbetet - en undersökning av kognitiv funktion efter strömgenomgång. [Electrical accidents at work - an investigation of cognitive function after exposure to electricity. In Swedish] Report 20 from Occupational and Environmental Medicine, Lund. 2013.

[13] Ek Å, Thomée S, Rådman L, K J, Gunnarsson L-G, editors. Perceived workplace safety culture among Swedish electricians. 19th Triennial Congress of the IEA; 2015: International Ergonomics Association.

[14] Sandelowski M. Whatever happened to qualitative description? Res Nurs Health. 2000;23(4):334-40.

[15] Graneheim UH, Lundman B. Qualitative content analysis in nursing research: Concepts, procedures and measures to achieve trustworthiness. Nurse Educ Today. 2004;24(2):105-12.

[16] Hsieh HF, Shannon SE. Three approaches to qualitative content analysis. Qual Health Res. 2005;15(9):1277-88.
[17] Braun V, Clarke V. Using thematic analysis in psychology. Qualitative Research in Psychology. 2006;3:77-101.

[18] Theman K, Singerman J, Gomez M, Fish JS. Return to work after low voltage electrical injury. Journal of Burn Care and Research. 2008;29(6):959-64.

[19] Kelley KM, Tkachenko TA, Pliskin NH, Fink JW, Lee RC. Life after Electrical Injury: Risk Factors for Psychiatric Sequelae. Ann N Y Acad Sci. 1999;888(1):356-63.

[20] Tkachenko TA, Kelley KM, Pliskin NH, Fink JW. Electrical Injury through the Eyes of Professional Electricians. Ann N Y Acad Sci. 1999;888(1):42-59.

[21] Primeau M. Neurorehabilitation of behavioral disorders following lightning and electrical trauma. NeuroRehabilitation. 2005;20(1):25-33.

[22] Primeau M, Engelstatter GH, Bares KK. Behavioral consequences of lightning and electrical injury. Semin Neurol. 1995;15(3):279-85.

[23] Stergiou-Kita M, Mansfield E, Colantonio A. Injured workers' perspectives on how workplace accommodations are conceptualized and delivered following electrical injuries. Journal of Occupational Rehabilitation. 2014;24(2): 173-88.

[24] Kosny A, Lifshen M, Pugliese D, Majesky G, Kramer D, Steenstra I, Soklaridis S, Carrasco C. Buddies in bad times? The role of co-workers after a work-related injury. Journal of Occupational Rehabilitation. 2013;23(3):438-49.

[25] Stergiou-Kita M, Mansfield E, Colantonio A, Moody J, Mantis S. What's gender got to do with it? Examining masculinities, health and safety and return to work in male dominated skilled trades. Work. 2016;54(3):721-33.

[26] Nielsen M. Adapting 'The Normal' - Examining Relations between Youth, Risk and Accidents at Work. Nordic Journal of Working Life Studies. 2012;2(2):71-85.

[27] Roesler ML, Glendon AI, O'Callaghan FV. Recovering from traumatic occupational hand injury following surgery: A biopsychosocial perspective. Journal of Occupational Rehabilitation. 2013;23(4):536-46.

[28] Clouser JM, Swanberg JE, Bundy H. Keeping workers safe: Does provision of personal protective equipment match supervisor risk perceptions? Am J Ind Med. 2015;58(8):886-96.

[29] Niza C, Silva S, Lima ML. Occupational accident experience: Association with workers' accident explanation and definition. Safety Science. 2008;46(6):959-71.

[30] Swedish National Electrical Safety Board. Elolyckor 2015 [Electrical accidents 2015, In Swedish]. http://www. elsakerhetsverket.se/globalassets/publikationer/rapporter/ elolycksrapport-2015.pdf2016.

[31] Tondel M, Blomqvist A, Jakobsson K, Nilsson T, Persson B, Thomée S, Gunnarsson L-G. Immediate and delayed outcomes after electrical injury. A guide for clinicians. [Elolyckor kan ge skador som visar sig efter lång tid. Det akuta omhändertagandet kan vara avgörande på sikt.] Lakartidningen. 2016;113:D7CL

[32] Swedish National Electrical Safety Board. Vägledning vid elolycka [Guidance on electrical accidents]. http://www. elsakerhetsverket.se/globalassets/publikationer/broschyrer/ vagledning-vid-elolycka.pdf2017. 